\title{
Rosabelle's Story
}

\section{Rosabelle Riese and Leslie Swartz}

\section{ROSABELLE'S STORY}

I contracted polio at the age of one and a half. My early childhood mostly was spent in hospitals which meant that I didn't spend a lot of time with my family.

My earliest recollection of the opposite sex was in primary school and, thinking back, I was actually not conscious of my disability affecting any friendship with boys. Everything just seemed normal to me. I didn't feel different and I was very competitive academically. During High School and University I had a few friendships but no romances. It's probably at this stage that I started feeling self-conscious of my disability, and began lacking self-confidence. I had many sexual encounters in many cases with no emotional attachment nor commitment from partners. I suppose you could call this my explorative period. This ranged from one night stands to fairly long periods of being intimate with one person.

R. Riese $(\otimes) \cdot$ L. Swartz $(\bowtie)$

Department of Psychology, Faculty of Arts and Social Sciences, Stellenbosch University, Stellenbosch,, South Africa

e-mail: lswartz@sun.ac.za

L. Swartz

e-mail: 1swartz@sun.ac.za

(C) The Author(s) 2021

X. Hunt et al. (eds.), Physical Disability and Sexuality, https://doi.org/10.1007/978-3-030-55567-2_5 
When I started doing sports I started meeting a new breed of man. These were guys who actually were involved with, and doing a service to, those with disabilities, in order for them to enjoy their Sport (Image 5.1).

Besides my other social activities, sport created another avenue where I could be in touch with the opposite sex on a social level, and at times on a more intimate level. There were no barriers to overcome. I was seen as a woman and a human being.

As I've travelled quite a bit during my sporting career I met one of my partners in Finland after my divorce. He was a shooting coach for the Dutch team. Once again, I had no barriers to work through as he was involved for many years with people with physical disabilities. Unfortunately he passed away after we had been living together for 5 years.

My ex-husband also has a disability. (Of all my relationships, only two men were people with disabilities.) We became proud parents during our marriage. Being able to bear a child and become a mother also strengthened my ense of my womanhood. I yearned for another child, but it

Image 5.1 Rosabelle pictured with a bouquet of flowers and medal, following a Para-Sport event (Photo by Rosabelle Riese)

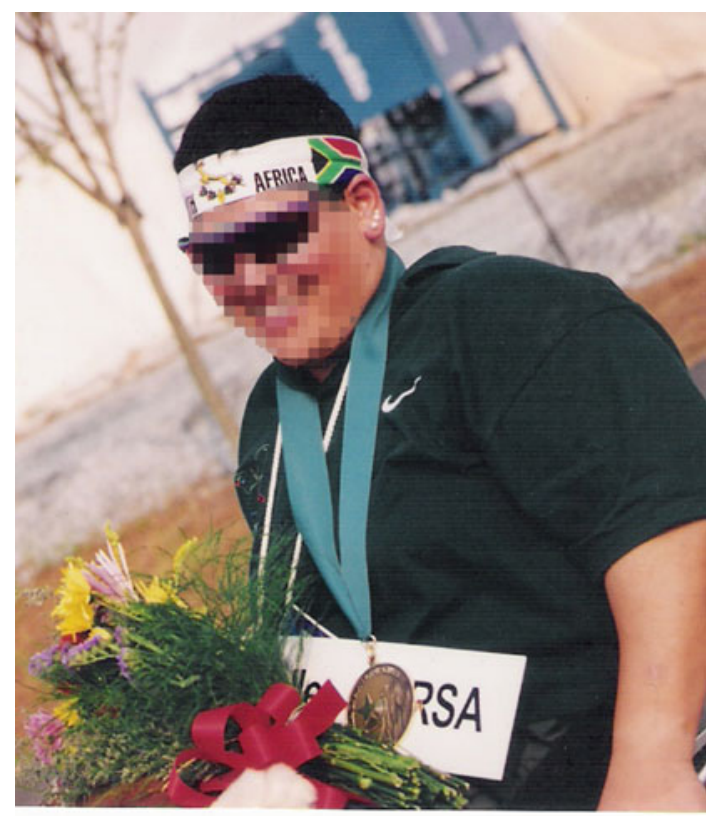


wasn't to be. My daughter, Marni, is now 26 years old and I am super proud of her.

At the start of some of my relationships I was always concerned about whether my partner would accept the shape of my body as I have scoliosis as well as deformities due to Polio, but it always got better as the relationship strengthened.

My self-confidence progressed and grew as I excelled in sport. Amongst my achievements are participation in three Paralympics (Bronze Medal in Shooting in Atlanta in 1996), three Gold medals in All Africa Games for Table Tennis and numerous Awards for Sportswoman with Disability, Flagbearer as well as Torchbearer, two Commonwealth Games, World Championships in Table Tennis, Shooting and Bowls. I also have South African titles in Powerlifting, Bowls, Table Tennis and Shooting. I am the only South African to have medalled in Air Pistol at Paralympics. My love for sport continues as I do coaching at times, and encourage others to participate in sport due to the fact that I had derived so much pleasure from it. Hard work in sport has its benefits, such as pride in one's own achievements, a healthy mind and body, meeting people, travelling the world and getting a taste of other cultures, to name a few.

Today I live in a self-help centre where 12 wheelchair users share and manage a house. Much has happened in my life and I am in the process of writing my autobiography. I am thankful for all the experiences in my life, some good and some not so good, but for now, I feel that life is great, and I know that being a sportswoman contributed to this.

$\mathrm{I}$ am, once again, in a relationship.

\section{A Brief Commentary on Rosabelle's Story: Disability, Embodiment and the Power of Sport}

Rosabelle tells her story to us as one of resilience-of facing difficulties and being able to overcome these, or to change her ideas of what life is and should be about. The very first sentences of Rosabelle's story tell us not only about a physical impairment ("I contracted polio"), but also about what happens to many children who are ill or have impairmentsthey spend time away from their families. This is something which can affect how people go on to relate to others in the world (Bowlby, 1983), but Rosabelle describes not being conscious of her disability in primary school, and not having difficulty relating to others. 
For Rosabelle, as for many other people, the sense of feeling different and of losing self-confidence came with adolescence, a time when people become more interested in sex. Rosabelle describes a time of sexual exploration and experimentation, which is common at that time of life. As for many people who don't feel comfortable about their bodies, though, it may be that Rosabelle would have done things a bit differently if she had felt more confident in herself (Hassouneh-Phillips \& McNeff, 2005; Liddiard \& Slater, 2018). Just after telling us of her lack of self-confidence, she describes sexual encounters "with no emotional attachment nor commitment from partners". For some people, and this could be true to some extent for Rosabelle, sexual encounters without emotional attachment or commitment may be satisfying. But when we read her story as a whole, she seems more appreciative of relationships on "a more intimate level", as she puts it. And for Rosabelle, what has enabled this has been her involvement in sport.

Rosabelle describes her introduction to being a sportswoman in very positive terms. Things began to happen and to change in a number of ways, including the following:

1. The people Rosabelle met. As she began her participation as a sportswoman, Rosabelle met "a new breed of men"-men who were assisting sportspeople with physical disabilities in their sporting careers.

2. Opportunities to socialise. Rosabelle speaks about being in touch with members of the opposite sex on a social level, and sometimes on a more intimate level. The experience of being together in the world of sport seems to be an equaliser, and thus opens the door to more satisfying relationships.

3. Opportunities to travel. One of the things many people with disabilities face, especially in countries which are not rich, is being isolated and cut off from the larger world. The internet has helped many people feel more connected, but virtual contact cannot replace the experience of being in other places and meeting different people (Swartz \& Marchetti-Mercer, 2019).

4. Opportunities to be seen as an equal. Rosabelle notes that when she got involved with sport, "there were no barriers to be overcome"-through sport, she has been able to be seen as someone who has something to offer, and something to offer through the abilities of her body. She has had the chance to see her body and 
what it can do being valued by others, and this may result in a greater sense of confidence in her body, and in her sexuality, more generally.

5. Opportunities to develop longer-term relationships. These relationships have been key for Rosabelle in terms of building her sexual self-confidence as she notes that her worries about how her body looks tend to lessen as relationships develop.

When we undertook our study, we were not looking for participants with particular histories of physical disability, but we were very pleased that somebody from a disability sport background did choose to join the project. Participation in physical activity is well known to provide a range of benefits - physical, mental and social-to many people, and there is no public health plan in the world today which will not reasonably recommend physical activity. Historically, though, many people with physical disabilities have been excluded from sport for a range of reasons, some of which are rather similar to the ways in which people have assumed that people with physical disabilities do not or should not have sex. For example, just as in the case of the way that many people think about people with physical disabilities and sex (Hunt, Swartz, Rohleder, Carew, \& Braathen, 2018), people may think about sport and physical activity as not really appropriate for people with physical disabilities (Howe, 2008). This may be partly due to a fear that participation in sport and physical activity may add to injuries and cause further disablement.

It is absolutely clear, though, that from the point of view of sportspeople with physical disabilities themselves, sport and physical activity is enjoyable and helpful in a range of ways. For many, sport is a way of gaining social acceptance and status, just as it has been for Rosabelle (Bantjes, Swartz, \& Botha, 2019; Conchar, Bantjes, Swartz, \& Derman, 2016). And social acceptance and status may well contribute, as is the case with Rosabelle, to greater sexual self-confidence. This is, of course, in addition to the confidence which may come from greater strength and prowess on the sports field.

Rosabelle's story is testimony to the potential and importance of sport and physical activity, but it is also important to remember that access to any kind of sport remains a challenge for many people with physical disabilities, especially in low- and middle-income countries (Swartz et al., 2016). The sexual rights and exclusions of people with physical 
disabilities are linked to other issues they face-and exclusion from sport and physical activity is one of these.

A final comment about the contribution of Rosabelle's story, and why it is placed so early in this book, is that it showcases the diversity of meaning of sexuality. When we asked people with physical disabilities to be part of the study, we noted that the topic was sexuality. However, when participants shared their stories, the links to what is traditionally considered sexuality (sexual acts, sexual health and maybe gender), were varied. Although Rosabelle's story mentions relationships and childbearing, sport is also a key theme and something central to Rosabelle's sense of her sexuality. This is something we would like the reader to bear in mind as you engage with this book; sexuality and sexual experience are as diverse as the people to whom they belong, and for people with physical disabilities, this diversity of experience makes an important contribution, as we will see, to our thinking about sexuality.

\section{REFERENCES}

Bantjes, J., Swartz, L., \& Botha, J. (2019). Troubling stereotypes: South African elite disability athletes and the paradox of (self-)representation. Journal of Community Psychology, 47, 819-832. https://doi.org/10.1002/jcop.22155.

Bowlby, J. (1983). Attachment: Attachment and loss Volume One (Basic Books Classics) (Attachment and Loss Series, Vol. 1, 2nd ed.). New York, NY: Basic Books.

Conchar, L., Bantjes, J., Swartz, L., \& Derman, W. (2016). Barriers and facilitators to participation in physical activity: The experiences of a group of South African adolescents with cerebral palsy. Journal of Health Psychology, 21, 152-163. https://doi.org/10.1177/1359105314523305.

Hassouneh-Phillips, D., \& McNeff, E. (2005). "I thought I was less worthy": Low sexual and body esteem and increased vulnerability to intimate partner abuse in women with physical disabilities. Sexuality and Disability, 23(4), 227-240.

Howe, D. (2008). The cultural politics of the Paralympic movement: Through an anthropological lens. London: Routledge.

Hunt, X., Swartz, L., Rohleder, P., Carew, M., \& Braathen, S. H. (2018). Withdrawn, strong, kind, but de-gendered: Non-disabled South Africans' stereotypes concerning persons with physical disabilities. Disability \& Society, 33, 1579-1600. Retrieved from https://doi.org/10.1080/09687599.2018. 1498768 . 
Liddiard, K., \& Slater, J. (2018). 'Like, pissing yourself is not a particularly attractive quality, let's be honest': Learning to contain through youth, adulthood, disability and sexuality. Sexualities, 21(3), 319-333.

Swartz, L., Bantjes, J., Rall, D., Ferriera, S., Blauwet, C., \& Derman, W. (2016). "A more equitable society": The politics of global fairness in Paralympic sport. PLoS ONE, 11(12), e0167481. Retrieved from http://dx.doi.org/10.1371/ journal.pone.0167481.

Swartz, L., \& Marchetti-Mercer, M. (2019). Migration, technology and care: What happens to the body? Disability o Society, 34, 407-420. https://doi. org/10.1080/09687599.2018.1519409.

Open Access This chapter is licensed under the terms of the Creative Commons Attribution 4.0 International License (http://creativecommons.org/licenses/ by $/ 4.0 /)$, which permits use, sharing, adaptation, distribution and reproduction in any medium or format, as long as you give appropriate credit to the original author(s) and the source, provide a link to the Creative Commons license and indicate if changes were made.

The images or other third party material in this chapter are included in the chapter's Creative Commons license, unless indicated otherwise in a credit line to the material. If material is not included in the chapter's Creative Commons license and your intended use is not permitted by statutory regulation or exceeds the permitted use, you will need to obtain permission directly from the copyright holder.

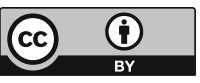

